\title{
ENTRE O CAMPO E A CIDADE: memória e preservação na Fazenda do Quilombo em Minas Gerais ${ }^{1}$
}

\author{
Elizabeth Aparecida Duque Seabra*
}

\section{Resumo}

O artigo discute como se elaboram reflexões sobre a história, a memória e a preservação de bens culturais a partir do contato com o patrimônio cultural em visitas educativas. Toma-se como pressuposto que os sujeitos em situações educativas de visita tornam-se parte constitutiva do movimento de produção e disponibilização de novos sentidos para o patrimônio cultural. Os visitantes elaboram narrativas onde explicitam suas escolhas e leituras, confrontando discursos de especialistas, acervos, objetos e visões historiográficas.

Palavras-chave: Memória. História. Patrimônio.

Lá estava, diante de João Brandão, o vetusto alcáçar bonacheiro, de pilotis anteriores à invenção deles, com varanda panorâmica que dava para comandar todo o vale de pastos e canaviais e abranger o fim-do-mundo, representado pelo horizonte de serranias azul-cinzentas, pois além destas não haveria nada senão o caos, o informe, o adoidado. Casa muito para se viver nela e despedir tudo que é vão desatino do outro lado da filosofia. João sempre sonhara em possuir um desses asilos de vida em paz, e só não comprara algum, primeiro por falta de cabedais, segundo porque não se lembrava de ler os classificados, terceiro porque receava que uma nova BR ou um novo loteamento nas imediações acabassem com o seu reino rural no melhor da festa bucólica. (Carlos Drummond de Andrade. Os dias lindos. Crônicas. Rio de Janeiro, 1986, p.20)

\section{1- Introdução}

\footnotetext{
${ }^{1}$ Versão ampliada e modificada de trabalho apresentado no VII Encontro Nacional Perspectivas para o Ensino de História, 2009, Uberlândia-MG.

* Mestre em História pela UFMG. Doutoranda no Programa de Pós-Graduação em Educação da UNICAMP. Área de concentração Educação, Conhecimento, Linguagem e Arte, grupo MEMÓRIA, HISTÓRIA E EDUCAÇÃO, sob orientação da Profa. Dra. Ernesta Zamboni. E-mail: bethseabra@uol.com.br.
} 
O personagem João Brandão, de Carlos Drummond de Andrade, é conduzido para uma fazenda mineira por força de uma misteriosa corrente da sorte. Lá, ele reflete sobre seu sonho de uma casa no campo. As fazendas mineiras povoam a literatura desde descrições feitas pelo viajante Saint-Hilaire, que se hospedara em uma delas no século XIX e estimulam ainda hoje nosso pensamento sobre um passado imaginado.

O próprio Drummond, que se considerava um "Fazendeiro do ar" ${ }^{2}$, em artigo para a Revista Globo Rural em 1985, fala da destruição da Fazenda Pontal em Itabira, como uma “falta do que não teve” e também como a dissolução de um "patrimônio tradicional de clãs”, os proprietários rurais em nome de uma urbanização e industrialização que "só aumentou o número de pobres e só distribuiu felicidade para pouca gente” (SILVA, 2009, p.22-23).

Raymond Williams (1989), que inspira o título desde artigo, também estabelece, através da pesquisa rigorosa com fontes literárias inglesas, a imagem de um campo relacionado com o passado e a cidade com uma visão de futuro. O presente lembra o autor de O campo e a cidade, fica sem um lugar de representação diante da dicotomia das imagens de retrocesso e progresso. Mas Williams também identifica, cuidadosamente, pontos de convergência mental entre o campo e a cidade, principalmente nas ficções de cidades do futuro que interagem com as antigas ficções bucólicas.

Pretendo neste artigo, indicar como experiências de sujeitos em presença de um patrimônio ${ }^{3}$ edificado de uma fazenda em ruínas, em Minas Gerais, podem inspirar pontes entre os lugares imaginários situados entre o "campo e a cidade”. As experiências de visitas educativas são capazes de ancorar memórias e expressar lógicas de sensibilidade histórica para com a preservação de um patrimônio.

Para dar lugar para a discussão dos sujeitos diante do patrimônio, apresento uma reflexão sobre uma ação de formação específica: uma visita a “Fazenda do Quilombo" no município de Pedro Leopoldo- $\mathrm{MG}^{4}$ que resultou na produção de um relato escrito e fotográfico contendo reflexões sobre a história, a memória e a preservação e, que entendo, como parte dos propósitos da pesquisa em desenvolvimento no doutorado. ${ }^{5}$

\footnotetext{
${ }^{2}$ Título de livro de poesias de Carlos Drummond de Andrade lançado em 1954.

${ }^{3}$ Ver discussão sobre patrimônio de Gonçalves (1996 e 2005)

${ }^{4}$ Pretendo desenvolver aqui uma reflexão sobre uma prática de formação realizada junto a alunas do Curso Normal Superior como parte das atividades acadêmicas das disciplinas História e Sociedade (Profa. Elizabeth Seabra) e Pesquisa e Produção do Conhecimento Prof. Shirley Miranda) oferecidas no $3^{\circ}$. período do Curso Normal Superior, primeiro semestre de 2005, no Instituto Superior de Educação das Faculdades Pedro Leopoldo na região metropolitana de $\mathrm{BH}$.

${ }^{5}$ Pesquisa de Doutorado junto ao Programa de Pós Graduação em Educação da Unicamp intitulada Visitas a museus: ensino de história, memória e patrimônio, sob orientação da Profa. Dra. Ernesta Zamboni.
} 
A questão central desenvolvida na tese de Doutorado em Educação, andamento, é, em que medida, práticas escolares envolvendo visitas a museus podem romper com os saberes disciplinares e pedagógicos incidindo diretamente sobre a produção de um conhecimento experiencial a ser mobilizado no ensino de história. Do ponto de vista mais amplo da pesquisa toma-se como suposto que os sujeitos - estudantes de licenciatura e professores/formadores em situações educativas de visita tornam-se parte constitutiva do movimento de produção e disponibilização dos conhecimentos acerca dos acervos de museus, construindo novos sentidos para o patrimônio cultural. Ao desenvolverem ações de planejamento, visitas e sistematização das práticas vivenciadas elaboram narrativas onde explicitam suas escolhas e leituras, confrontando discursos de especialistas, profissionais de museus, acervos, objetos museais e visões historiográficas, conflitantes entre si, apresentadas em sua formação acadêmica e profissional.

\section{2- Visita à Fazenda do Quilombo - memória e preservação}

As experiências de visita na Faculdade de Pedro Leopoldo eram desenvolvidas pelas diversas disciplinas curriculares, envolviam professores/formadores de diferentes cursos de formação/licenciaturas como Geografia, Pedagogia, Letras e História, além de turmas distintas de um mesmo curso. A prática de visitas desdobrava-se, em alguns casos, em atividades de estágio e projetos de intervenção articulando educação patrimonial, ensino de história, visitas a museus e parcerias com escolas de educação básica.

A preparação das visitas compreendia desde contatos com órgãos governamentais para agendamento, autorização de órgãos como o Instituto Estadual do Patrimônio Histórico e Artístico de MG para visitação a sítios tombados, a apresentação e discussão em sala de aula de materiais sobre os locais a serem visitados, visitas virtuais e elaboração de roteiros de observação e registro. No caso aqui destacado, o contato com a proprietária da Fazenda foi direto, já que se tratava de sítio particular.

Os trabalhos desenvolvidos, em geral, articulavam objetivos relacionados às temáticas específicas das disciplinas curriculares e outros voltados à questão da memória e patrimônio cultural. Assim, à medida que o trabalho na Fazenda do Quilombo envolveu duas professoras e duas disciplinas de um mesmo período, foram estabelecidos como objetivos da visita: 
Identificar formas de expressão cultural de diferentes grupos sociais a partir da observação do patrimônio local. (Orientações para trabalho de Campo Curso Normal Superior. FIPEL, 2005)

Após a visita, foram elaborados pelas visitantes, textos individuais contendo reflexões que responderiam aos objetivos propostos e avaliassem os aspectos mais relevantes da visita. Demais materiais (fotografias, entrevistas etc.) recolhidos, ou produzidos, durante a visita também foram apresentados em sala de aula. A turma, com o auxílio de uma monitora do curso de história, produziu um relatório-síntese que reunia trechos dos trabalhos individuais e fotografias em formatos digitais e impresso.

Percorrendo todo esse trajeto de contato com o patrimônio cultural, as experiências de visita geram conhecimentos à medida que permitem uma aprendizagem mediada pela observação e pela própria experiência. Autores como Shön (1997) falam em uma epistemologia da prática que é a passagem de um tipo de conhecimento na ação, dinâmico, espontâneo e difícil de ser verbalizado para uma reflexão na ação como uma reflexão cognitiva consciente do sujeito, um pensar sobre e durante. Pode-se pensar assim, em analogia ao tema do campo e da cidade, que há, nas visitas, uma dupla convergência entre uma lógica objetiva que visa à produção de conhecimentos e outra lógica subjetiva que instaura uma subjetividade poética constituindo a relação dos sujeitos com o patrimônio cultural.

Ao refletir e avaliar sobre esse tipo de prática de formação é possível apontar uma suposta abstração advinda dos relatos e narrativas individuais que, por sua vez, mobilizam um horizonte de referências e ressonâncias mais amplo: idealizado e suposto. Dito de outra forma, a análise das narrativas de visita permite traduzir conceitos disponíveis e muitas vezes, discordantes, principalmente de memória e história, que circulam ao nível das próprias práticas, apostando em sua emergência quando os sujeitos (antes, vistos apenas como professores e estudantes) e reconhecem seu pertencimento a lugares e identificam objetos simbólicos a serem ressignificados e usados em situações pedagógicas diversas.

Para trabalhar com as experiências concretas de visita é preciso constituir a materialidade destas práticas através da elaboração de uma narrativa historiográfica ${ }^{6}$, entendida como uma mediação histórica que opera a inclusão da interpretação do presente e do futuro na memória no passado inserindo-lhe um conteúdo experiencial. Operações de narrar são próprias da vida prática e constituem a consciência histórica como fundamento e

\footnotetext{
${ }^{6}$ Em Rüsen (2001) parece-me possível apontar para o fim da dicotomia conhecimento acadêmico/realidade concreta ou vida cotidiana, pois para ele a teoria da história, em seus fundamentos, se constitui na vida prática corrente.
} 
pressuposto do conhecimento histórico, pois formularam representações de continuidade temporal instituindo identidades por meio da memória. (RUSEN, 2001, p.64-5)

Pode-se pensar também em uma “pedagogia da memória e da narrativa” aproximando na pesquisa "os fios culturais dispersos, compartimentados, hierarquizados, pelas práticas contemporâneas (...) entrelaçando as concepções de memória, história e educação” (GALZERANI, 2004, p.316).

Um dos sentidos de memória, se que entrelaça ao de narração, é a imagem de “rememoração”. Lida a partir da obra de Benjamin o trabalho de rememoração possibilita uma ruptura com a racionalidade instrumental descompromissada com as ações no presente, com o vivido, ao criar acepções mais amplas do ser humano (sujeito) que elabora suas visões de mundo e sensibilidades (cultura) como dimensões instituintes da sociedade e não como produtos das relações sociais já dadas. Tecelão da memória, narrador de si mesmo, o sujeito não faz autobiografia, mas submete-se à dinâmica imprevisível do lembrar (memória involuntária) à prova temível da perda, da dispersão, do esquecimento. Entrelaça diversas vidas em diversos tempos, questiona as relações e sensibilidades sociais existentes no presente e busca rumos a serem construídos no futuro (GALZERANI, 2002, p.63).

A contribuição do conceito de memória (rememoração) articulado à concepção de história, e não em oposição ou distanciado dela, aponta um movimento estético criativo situado no próprio sujeito que não evade dos conflitos presentes. Do ponto de vista metodológico, abrem-se perspectivas de uma "viagem no tempo" com direito a ida e volta: pensar as relações com o vivido, o comprometimento com as ações no presente, abertura coletiva para dimensões sensíveis dos seres humanos focalizados, reconhecimento dos atributos humanos involuntários, inconscientes e o desapossar de uma concepção absoluta de verdade são algumas dos fundamentos para "fazer teoria da prática” ou um diálogo entre a diversidade cognitiva dos saberes e a pluralidade de seus vínculos historicamente dados ou rememoráveis (GALZERANI, 2004, p.297/8).

Assim, aprender sobre um objeto pode ser pensado como relacionado não apenas a uma dimensão cognitiva, mas com figuras do saber mais amplas. A necessidade de aprender entendida de dentro, do próprio campo de ação/observação cria, ao mesmo tempo, obstáculos e possibilidades ao sujeito que se propõe a descrever e analisar a própria situação educativa/formativa. 


\section{3- Fazendeiras do ar}

[...] os cavalos pousam mais no ar do que no chão, a distância deixa de ser referência, rumo não tem sentido. [...] O espetáculo do mundo apresenta-se múltiplo e simultâneo aos olhos do cavaleiro e da comitiva. (Carlos Drummond de Andrade. Os dias lindos. Crônicas. Rio de Janeiro, 1986, p.29)

A decisão sobre qual lugar a ser visitado era tomada conjuntamente com cada turma. Entretanto, havia uma diferenciação entre as sugestões feitas pelas turmas de História e aquelas apresentadas pelas demais licenciaturas, em especial a Pedagogia. Enquanto a história sugeria visitar lugares como grandes museus no Rio de Janeiro, São Paulo e cidades coloniais mineiras, as alunas da Pedagogia propunham locais da própria cidade como parques, fazendas, festas populares e instituições que trabalhavam com inclusão social. Assim, as turmas da pedagogia visitaram no ano de 2001 o Salão do Encontro, uma ONG em BetimMG, pois tinham interesse na discussão sobre inclusão e diversidade. Outra turma foi observar as Congadas em Vespasiano, pois havia um estudante que participava das manifestações populares e o debate sobre a questão religiosa mobilizava bastante a turma. Também foi organizada pela Coordenação do Curso uma visita ao Museu de Artes e Ofícios, em BH, como preparação para uma mostra sobre o Ofício Docente e a Cidade organizada em 2006, conjuntamente, pelos cursos Normal Superior/Pedagogia ${ }^{7}$ e História com o apoio da Secretaria Municipal de Educação de Pedro Leopoldo.

A visita à Fazenda do Quilombo foi sugerida por uma aluna que já residira no local quando criança. O relato da visita elaborado por essa aluna ajuda a pensar como um indivíduo faz o percurso das suas "perturbações pessoais originadas no meio mais próximo” as “questões públicas da estrutura social” (MILLS, 1975, p.14).

A elaboração dos relatos, primeiro individual e depois coletivamente, permitem criar uma opção e alternativa para compreender e fazer a mediação entre os sujeitos e a estrutura (o visitante e fazenda), a história individual (biografia) e a memória social. Os visitantes mobilizam, em primeiro plano, suas memórias pessoais, localizam-se historicamente em seu tempo, compreendem sua experiência e avaliam o percurso estabelecendo ligações mais amplas com a sociedade e questões de interesse público com a preservação do patrimônio

\footnotetext{
${ }^{7}$ Com a aprovação de novas diretrizes para os cursos de Pedagogia pelo CNE em 16/5/2006 a FIPEL reformula seu curso Normal Superior e passa a oferecer o Curso de Pedagogia com formação voltada para as séries iniciais e educação infantil.
} 
local. O que Dileuza encontra na fazenda é mais que a perda da infância e de um tempo passado. Ela se encontra com o seu presente e nos diz:

É muito triste ver que você passou sua infância em um lugar, que a meu ver, fez parte da história e de repente você retorna ao local e se depara com tamanho descaso. A atual dona da fazenda parece não ter muito interesse em estar preservando o patrimônio do local. (Dileuza Aparecida dos Santos Lima. FIPEL, 2005)

A fala de Dileuza traz esse vínculo de pertencimento ao local e, simultaneamente, indica que esse lugar não é isolado no espaço e no tempo. É privado, mas guarda interesses públicos. Para além da importância em sua vida, suas lembranças pessoais se cruzam na materialidade da fazenda (seu patrimônio) - casario, objetos, móveis - com a história de outros sujeitos.

Em todos os relatos da visita há metáforas de decadência, de ruínas, de abandono: a proprietária não tem a intenção de reformar, restaurar a antiga fazenda, os custos são altos. Hoje utilizada para lazer não se dedica a nenhuma atividade produtiva. A escola foi desativada. Essas imagens também são materializadas nas fotografias produzidas pelas visitantes.
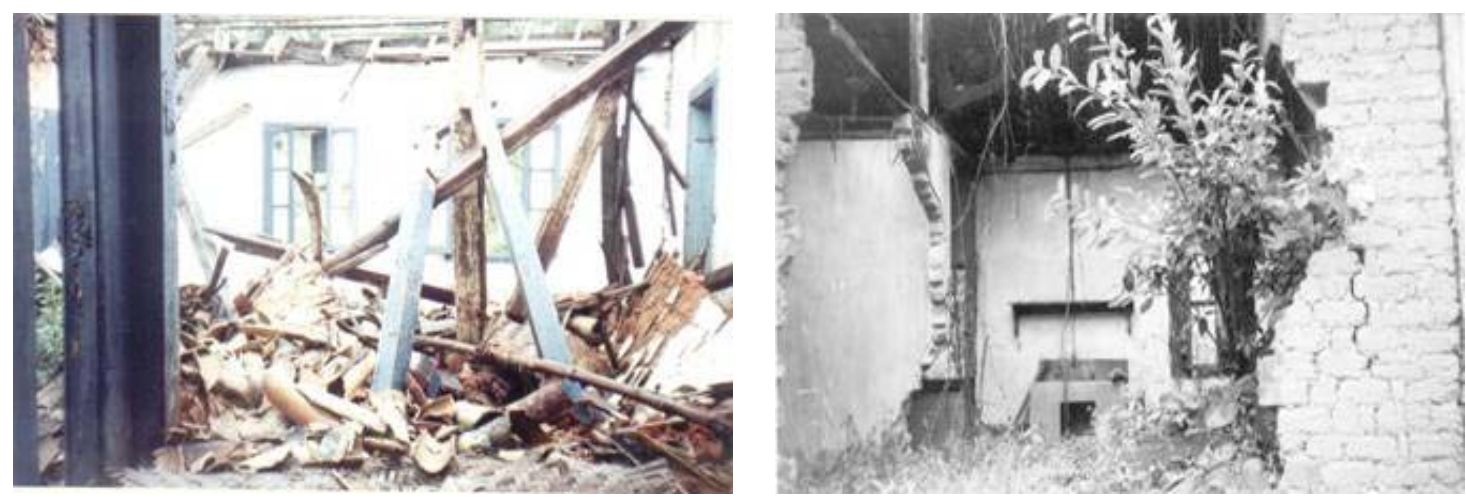

Fotos tiradas em 30/05/2005- Fazenda do Quilombo- Pedro Leopoldo/MG

A exceção é a sede principal, como nos diz outra aluna:

A sede principal está bastante conservada, existem alguns móveis antigos até uma cadeira militar da época do império. Algumas louças antigas enfeitam os móveis do alpendre. Há uma grande plantação de orquídeas e uma linda piscina aos arredores da casa. Havia também uma imagem de santo que o encarregado não soube dizer qual, no oratório do alpendre. Na fazenda havia uma capela, várias imagens de santos e uma escola que hoje só restam algumas cadeiras em forma de bancos de igreja. A primeira professora da escola chamava D. Efigênia e as turmas eram multiseriada. (Nanci Soraia Salomão Costa. FIPEL, 2005) 
O sentimento de curiosidade, de ansiedade predomina numa primeira temporalidade: 0 tempo de duração da visita, uma manhã de sábado. São estas as forças que mobilizam a observação do cenário. A mata nativa de 400 hectares e as orquídeas são fotografadas. Os móveis, um verdadeiro encantamento pela cadeira do tempo do imperador. Tiramos uma foto todas ao redor dela. Por que os objetos antigos despertam o sentido de passado, de escoar do tempo e de perda?
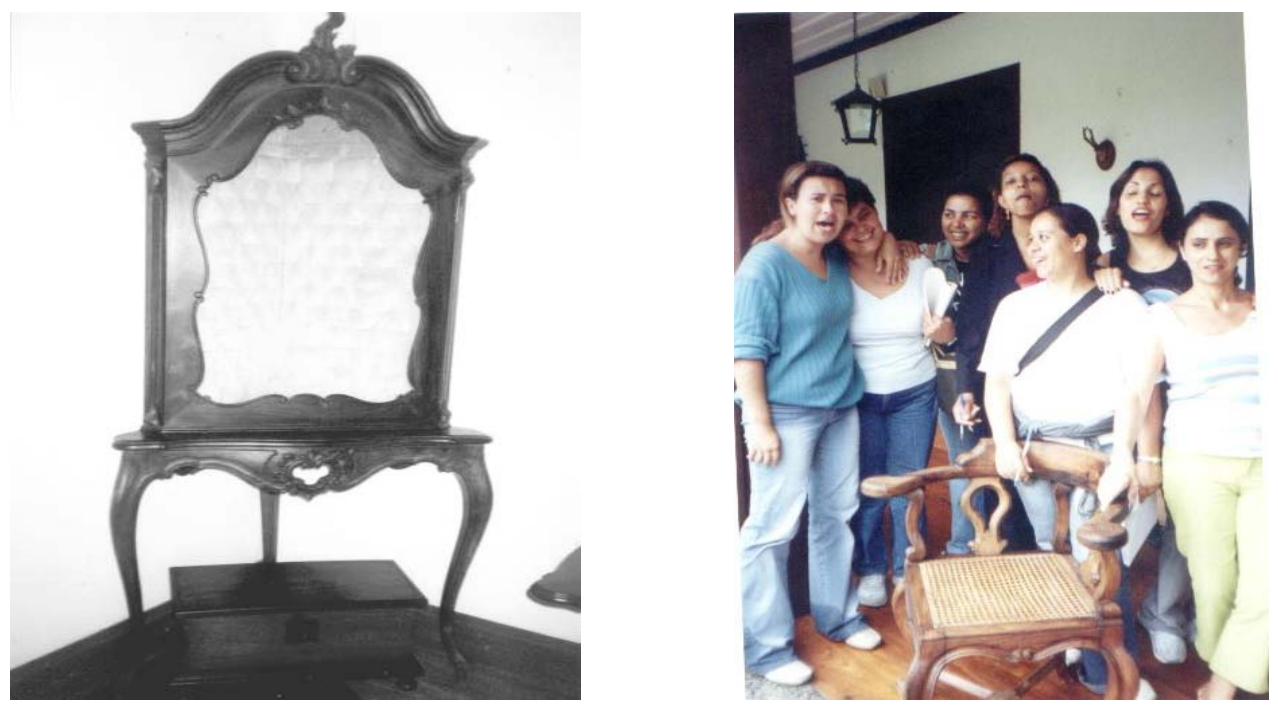

Fotos tiradas em 30/05/2005- Fazenda do Quilombo- Pedro Leopoldo/MG

À medida que as visitantes adentravam a fazenda uma segunda temporalidade começava a surgir e foi retomada, posteriormente, no momento da escrita dos relatos: a nostalgia, as reminiscências e lembranças de tempos e lugares que nunca vimos ou vivemos em outra época. “Gostei muito do local onde trouxe muita saudade de uma pequena fazenda do meu avô” diz Nilda Betiene Alves. “O estilo colonial relembra casas inglesas”[...] relaciona Mariléia da Silva Salvador.

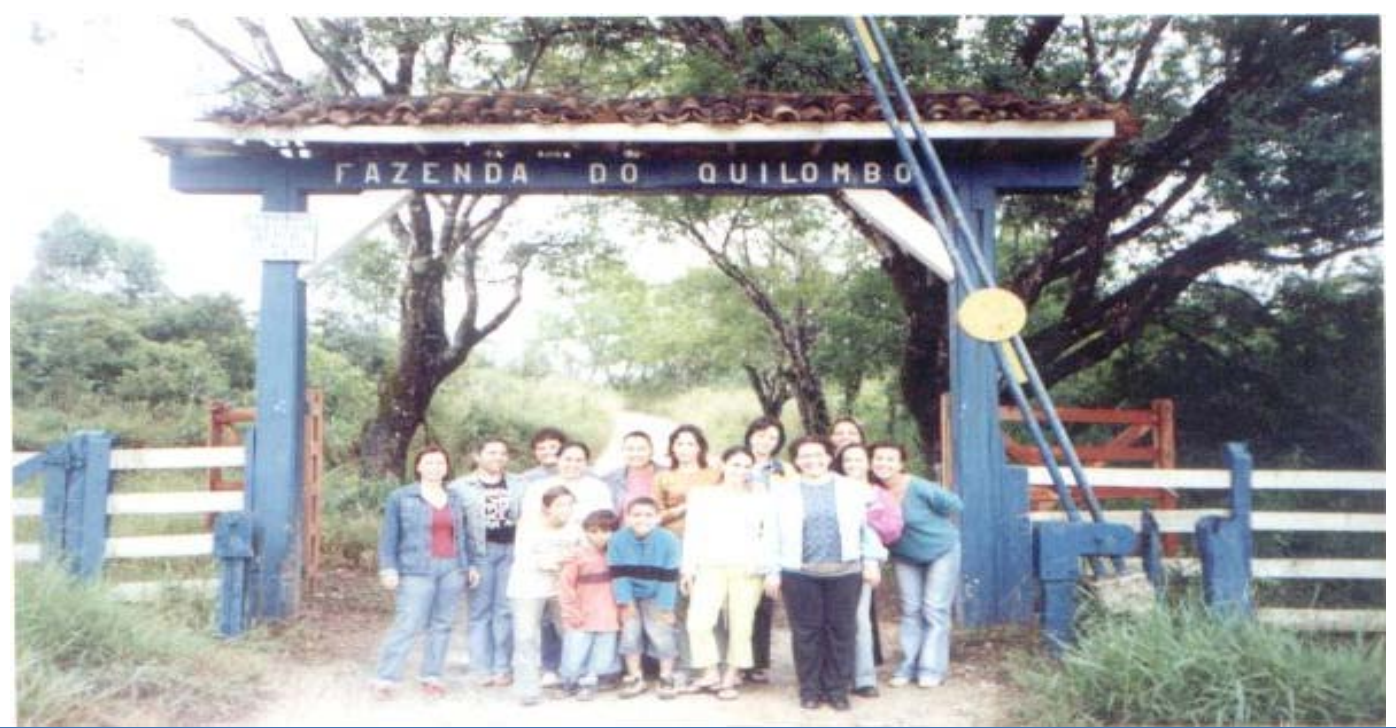


A memória surge aqui não como um resgate do passado, mas vinculada ao presente, à construção da identidade pessoal e profissional. Como fragmento que puxa os fios entre presente e passado. Aparece como resíduo, como rastro, como fresta na qual entreolhamos. O fato de ter existido uma escola naquele espaço é observado atentamente por todas. O interesse no funcionamento dessa escola é digno de nota: o nome da primeira professora, o tipo de organização da classe multiseriada, o mobiliário e o seu desaparecimento.
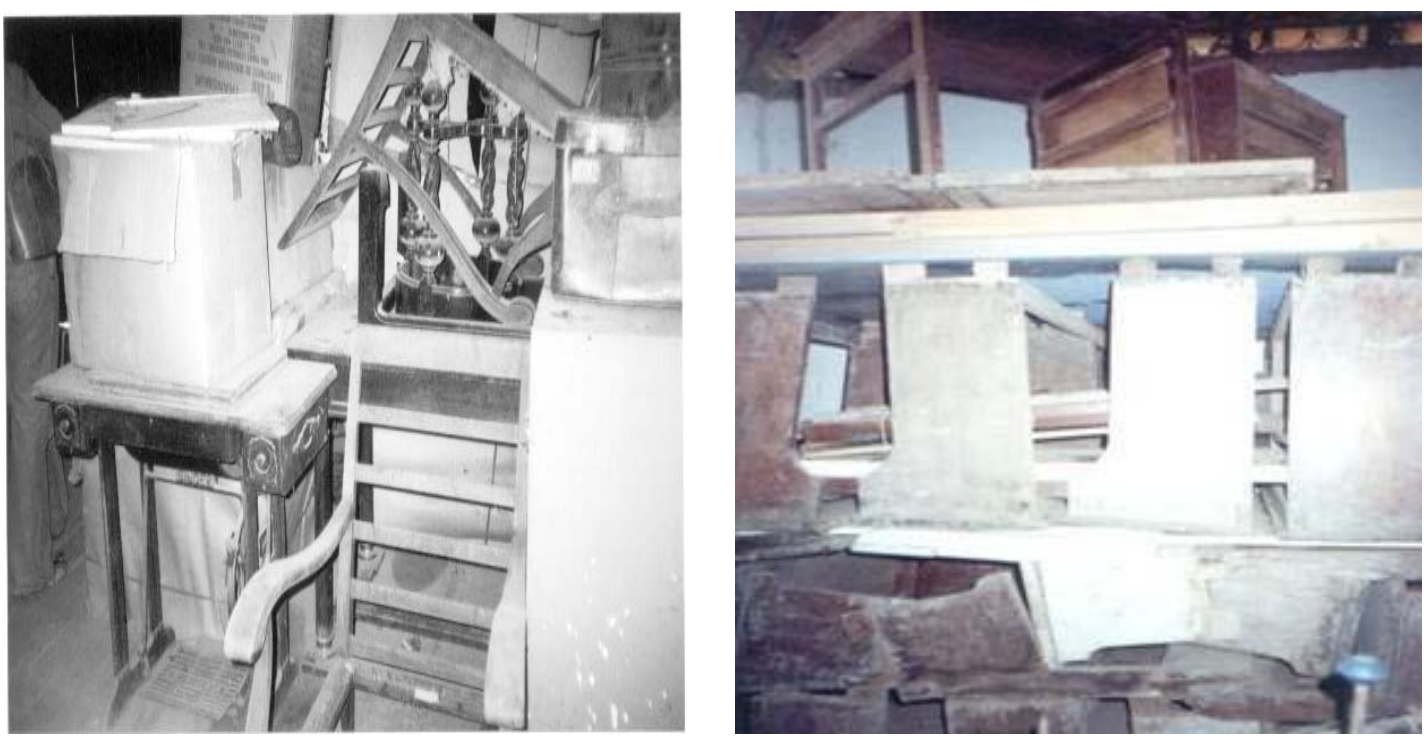

Móveis e carteiras que pertenciam à escola que existiu na Fazenda do Quilombo

O que fazer com esse “patrimônio”? A quem pertence essa memória? Vários relatos responsabilizam diretamente a proprietária pelo destino dos objetos e sua má conservação. Uma aluna, porém, produz uma nova categoria pública a ser responsável pela preservação: o museu.

[...] deparamos com casas, pequenas colônias destruídas, móveis encostados como: ardo, cadeiras de ferro, cama de mola, máquina de costura, lustre, barco etc. Materiais que para ela tem valor pelo seu abandono, mas que podiam ser doados a um museu. (Vânia Cristina Araújo. FIPEL, 2005)

A imaginação museal de Vânia aponta que um dos sentidos de museu está relacionado a lugar de coisas velhas ou antigas. É para lá que vão os objetos sem utilidade. Essa ideia será retomada e explorada em outro momento da pesquisa. Fica aqui o registro. 
Em outro relato aparece uma fundamentação para o cuidado com a manutenção da “materialidade dos objetos”. Eles pertencem à comunidade do entorno, Vera Cruz. São objetos de cultura e permanecem como "testemunhos" por mais tempo que os relatos orais. Veja a fala da aluna:

Ao pensar no patrimônio que é a fazenda do Quilombo pertencente à Vera Cruz sendo tratada com tanto descaso por seus donos e sendo restaurada simplesmente por luxúria, e fechando os olhos para os antepassados e sua cultura. A memória dos patrimônios se não for restaurado por causa do tempo, perdemos grande parte do patrimônio e vamos ter acesso apenas as lembranças contadas, ou seja, relatadas pelas pessoas que fizeram parte do cenário. (Daniela Junia da Silva. FIPEL, 2005)

O relatório foi elaborado a partir do Roteiro de Observação apresentado antes da visita e das conversas com o encarregado pela fazenda. Não foram consultados outros documentos escritos sobre a região. Esse tipo de prática também não tinha por objetivo produzir um material pedagógico sobre o local visitado. Entretanto, se constrói na visita um sentido sobre o tempo e um conhecimento histórico com o auxílio de conceitos empíricos de entendimento e esquemas de imaginação. As alunas constituem uma narrativa, ou interpretação, do passado reconceitualizando a realidade imediata que observam e elaboram uma autorreflexão. Refletem sobre a matriz disciplinar da História. Assim se posiciona outra aluna:

O passeio foi muito bom e agradável. Passei por caminhos que nunca havia passado, fiquei ansiosa e curiosa em poder saber um pouco da história da fazenda, e que ali já viveram escravos. (Silvia Luiz Peçanha. FIPEL, 2005)

\section{4- Considerações finais: os sujeitos entre a memória, a história e o patrimônio}

Podemos dizer que os relatos das visitas trazem uma série de “efeitos formativos” nos estudantes e professores/formadores. Desencadeiam perguntas sobre a identidade, verbalizam sentimentos, pensamentos, aspectos de suas experiências sociais e estimula a reflexibilidade. As narrativas dos alunos também validam algumas construções teóricas à medida que operam com a tradução de concepções simbólicas particulares e localizadas em uma consciência prática e, outra, discursiva de caráter mais amplo.

Os relatos também permitem reconhecer e dar visibilidade pública e social a realidades locais, multiculturais e contribuem para contrariar formas hegemônicas de produção de conhecimento já instituídas e institucionalizadas nas rotinas de formação. 
A primeira consideração, ao tratar do contato de estudantes de licenciatura com o patrimônio cultural em suas múltiplas dimensões, é indicar que a visita pode ser pensada numa dupla dimensão da noção de experiência tal como a expressa Dominicé uma "forma pela qual o saber se forja nas situações concretas, como se constrói através da ação ou se desenvolve nos acontecimentos existenciais” (apud. Bueno 2002, p.8).

Entretanto, não podem ser desconsideras as limitações institucionais, bem como, uma avaliação do papel específico das agências e programas (currículos, projetos pedagógicos, legislação e condições do exercício do “ofício” de alunos e professores formadores), na experiência aqui destacada, mas interessa apostar em categorias analíticas que apontem para o entendimento de como se produzem perspectivas críticas e estratégias de apropriação dos referenciais simbólicos, uso de artefatos culturais e da memória social no interior das experiências de formação dentro, e fora, das instituições formadoras. ${ }^{8}$

Os visitantes, assim como qualquer indivíduo, se posicionam como sujeitos complexos no jogo cultural da contemporaneidade confrontando, negociando, resistindo, recriando o que lhe é apresentado e compondo um repertório próprio de saberes e práticas.

Investigar esse tipo de prática de formação implica também dizer que os estudantes de licenciatura durante os seus processos de formação são capazes de constituírem de modo autônomo no plano cognitivo e cultural. Não são simplesmente receptores de programas e propostas por melhores e bem intencionadas que sejam. Também não são dominados, menores, com déficits, pobres em recursos e capitais. Por outro lado, analisar uma prática de formação na qual o pesquisador está implicado diretamente na ação provoca uma tensão e ambiguidade, já que se cria um lugar de fronteira entre um “olhar de fora” para compreender e um "estar dentro" dos processos de socialização. Ser participante e ao mesmo tempo recolher dados. "Saber-pensar de fora" e "saber-fazer de dentro" se encontram e devem provocar a reflexibilidade.

A análise centrada no cotidiano das rotinas da ação e na negociação dos sentidos e usos do conhecimento disciplinar (histórico) constitui um duplo objeto de experiência, de um lado, um elo dos sujeitos que se materializa nos relatórios e fotografias e, de outro lado, um conhecimento prático e emocional codificado em evidências fragmentárias, um posicionamento parcial e localizado do sujeito frente ao debate, às interações, aos itinerários e suas experiências pessoais e do grupo.

\footnotetext{
${ }^{8}$ Ver discussão sobre “lugares de memória” e formação de professores em MIRANDA, 2008.
} 


\title{
BETWEEN THE COUNTRY AND THE CITY: memories and preservation of the Fazenda do Quilombo (Quilombo Farm) in Minas Gerais
}

\begin{abstract}
The article discusses how to reflect on history, memory and preservation of cultural property from the contact with cultural heritage in educational visits. We presuppose that the subjects in situations of educational present and offer new directions for cultural heritage. The visitors create narratives, where they explain their choices, confronting speeches and lectures from experts, collections, objects and historiographical visions.
\end{abstract}

Keywords: Memory. History. Heritage.

\section{Referências}

BUENO, B. O. et. alii. Histórias de vida e autobiografias na formação de professores e profissão docente (Brasil, 1985-2003). Educação e Pesquisa, v. 32, n.2, p.385-410, maio/ago.2006.

FIPEL - FACUDADES INTEGRADAS DE PEDRO LEOPOLDO. Instituto Superior de Educação de Pedro Leopoldo - Projeto Pedagógico do Curso de História. HISTÓRIA. Pedro Leopoldo, MG. 2004.

FIPEL - FACUDADES INTEGRADAS DE PEDRO LEOPOLDO. Instituto Superior de Educação de Pedro Leopoldo. Fazenda do Quilombo. Memória e preservação (Relatório de visita). $3^{\circ}$. período Curso Normal Superior. Pedro Leopoldo, 2005.

GALZERANI, Maria Carolina Bovério. Memória, História e (re) invenção educacional: uma tessitura coletiva na escola pública. In: MENEZES, Maria Cristina (Org.) Educação, memória, história: possibilidades, leituras. Campinas. SP: Mercado das letras, 2004, p. 287330.

Imagens entrecruzadas de infância e de produção de conhecimento histórico em Walter Benjamin. IN: FARIA, Ana Lúcia Goulart de, et alii (Org.) Por uma cultura da infância: metodologias de pesquisa com crianças. Campinas, SP: Autores Associados, 2002. p. 48-68.

GONÇALVES, José Reginaldo Santos. A retórica da perda: os discursos do patrimônio cultural no Brasil. Rio de Janeiro: Editora UFRJ; IPHAN, 1996.

Ressonância, materialidade e subjetividade: as culturas como patrimônios.

Horizonte antropológico. [online]. 2005, vol.11, n.23, pp. 15-36. 
MILLS, C. Wright. A imaginação sociológica. Rio de Janeiro: Zahar, 1975.

MIRANDA, Sônia Regina. Lugares de memória, espaços de formação: elos invisíveis na constituição do conhecimento histórico de professores. In: ZAMBONI, E. e FONSECA, S.G. Espaços de formação do professor de história. Campinas, Papirus, 2008. p.261-280

RÜSEN, Jörn. Razão histórica: teoria da história; os fundamentos da ciência histórica. Brasília: UNB, 2001.

SHÖN, Donald. Formar professores como profissionais reflexivos. In: NÓVOA, A. (Org.). Os professores e a sua formação. Lisboa: Dom Quixote, 1997. p.77-92.

SILVA, Gislene. O sonho da casa de campo: jornalismo e imaginário de leitores urbanos. Florianópolis: Insular, 2009.

WILLIAMS, Raymond. O campo e a cidade: na história e na literatura. São Paulo: Companhia das Letras, 1989. 